in vivo $33: 1609-1614$ (2019)

doi:10.21873/invivo.11644

\title{
Retrospective Analysis of Trabectedin Therapy for Soft Tissue Sarcoma
}

\author{
KUNIKI KAWAGUCHI ${ }^{1}$, KENJI NAKANO ${ }^{1}$, TETSUYA URASAKI ${ }^{1}$, NAOKI FUKUDA ${ }^{1}$, \\ SHINICHIRO TAIRA ${ }^{1}$, MAKIKO ONO ${ }^{1}$, JUNICHI TOMOMATSU ${ }^{1}$, \\ MASATOSHI NISHIZAWA ${ }^{1}$, KEISUKE AE ${ }^{2}$, SEIICHI MATSUMOTO ${ }^{2}$ and SHUNJI TAKAHASHI ${ }^{1}$ \\ ${ }^{1}$ Department of Medical Oncology and ${ }^{2}$ Department of Orthopedic Oncology, \\ Cancer Institute Hospital of the Japanese Foundation for Cancer Research, Tokyo, Japan
}

\begin{abstract}
Background/Aim: Trabectedin is a synthetic antineoplastic agent approved for advanced soft tissue sarcoma (STS) in Japan. The aim of this study was to evaluate the efficacy and safety of the Japan-approved dose of trabectedin for advanced STS. Patients and Methods: We retrospectively reviewed 38 patients with advanced STS who received salvage chemotherapy with trabectedin. Results: The overall response and disease control rates were $16 \%$ (5 patients) and 67\% (20 patients), respectively. The median progression-free and overall survival were 7.3 and 17.8 months, respectively. There were no significant differences between patients with liposarcoma or leiomyosarcoma and those without, or between patients with TRS and those without. The most common grade 3-4 AEs were elevated transaminases and neutropenia. Conclusion: Trabectedin $1.2 \mathrm{mg} / \mathrm{m}^{2}$, as the approved dose in Japan, showed similar efficacy to the dose of $1.5 \mathrm{mg} / \mathrm{m}^{2}$ used in Western countries. Trabectedin could be an option for advanced STS in Japan, regardless of histological subtype.
\end{abstract}

Soft tissue sarcomas (STSs) are defined as a rare group of heterogeneous mesenchymal tumors (1). According to data from the national soft tissue tumor registration in 2012, a total of 1,597 patients were registered with STS in 2012 in Japan (2). STS can occur in almost any anatomical site, including the limbs (60\% of cases), chest, abdomen,

This article is freely accessible online.

Correspondence to: Dr. Shunji Takahashi, Department of Medical Oncology, Cancer Institute Hospital, Japanese Foundation for Cancer Research, Ariake, Tokyo 135-8550, Japan. Tel: +81 335200111, Fax: +81 335200141, e-mail: s.takahashi-chemotherapy@jfcr.or.jp

Key Words: Soft tissue sarcoma, L-sarcoma, translocation-related sarcoma, overall survival, progression-free survival. retroperitoneum, and head and neck. More than 50 histological subtypes have been identified according to the World Health Organization classification, each with a specific biology and clinical outcome $(1,3)$. Specific fusion genes are known to be associated with approximately $20 \%$ of STSs, and detection of these fusion genes is useful for diagnosis, as well as for clarifying the biological characteristics and informing treatment decisions $(4,5)$.

The prognoses of patients with early-stage STS have recently improved as a result of multidisciplinary approaches including surgery, radiotherapy, and systemic therapy, leading to a 5-year overall survival (OS) rate of approximately $80-90 \%$. However, the 5-year OS in patients with advanced stage STS is only about $50 \%$, implying that the prognosis is still poor (6).

Systemic chemotherapy is typically performed in patients with unresectable STS. Doxorubicin is the mainstay of firstline therapy, with a response rate of approximately 10-30\% (7-9). Previous studies have demonstrated the efficacy of molecular targeted agents and new antineoplastic agents, and the options for second- or later-line treatment have increased; however, the positioning of these agents has not been established $(10,11)$.

Trabectedin is a marine-derived, semisynthetic DNAbinding protein that exerts an antineoplastic effect by binding to the minor groove of DNA and bending the DNA towards the main groove (12). This agent has been approved for clinical use in Europe since 2007 and has been used to treat patients with unresectable advanced or recurrent STS $(13,14)$. Following a clinical trial targeting translocation-related sarcoma (TRS), trabectedin was finally approved in Japan in 2015. However, reports on the clinical efficacy and safety of trabectedin in Japan are currently lacking.

In this study, we retrospectively reviewed patients with recurrent STS who were treated with trabectedin, with a particular focus on its efficacy in patients with L-sarcoma (leiomyosarcoma plus liposarcoma) and TRS. 
Table I. Patient characteristics.

\begin{tabular}{|c|c|}
\hline $\begin{array}{l}\text { Demographic and baseline c } \\
\text { haracteristics of } 38 \text { patients }\end{array}$ & No. of patients (\%) \\
\hline \multicolumn{2}{|l|}{ Age (years) } \\
\hline$\geq 65$ & $5(13.2)$ \\
\hline$<65$ & $33(86.8)$ \\
\hline Median (range) & $47(21-74)$ \\
\hline \multicolumn{2}{|l|}{ Gender, $\mathrm{n}(\%)$} \\
\hline Male & $18(47.4)$ \\
\hline Female & $20(52.6)$ \\
\hline \multicolumn{2}{|l|}{ Baseline ECOG } \\
\hline 0 & $28(73.7)$ \\
\hline 1 & $9(23.7)$ \\
\hline 2 & $1(2.6)$ \\
\hline \multicolumn{2}{|l|}{ Histology } \\
\hline L-sarcoma & $17(44.7)$ \\
\hline Leiomyosarcoma & $5(13.2)$ \\
\hline Liposarcoma & $12(31.6)$ \\
\hline Synovial sarcoma & $9(23.7)$ \\
\hline \multicolumn{2}{|l|}{ Primary site } \\
\hline Lower limb & $20(52.6)$ \\
\hline Upper limb & $2(5.3)$ \\
\hline Retroperitoneum & $10(26.3)$ \\
\hline Abdominal cavity & $1(2.6)$ \\
\hline Head and neck & $1(2.6)$ \\
\hline Trunk & $4(10.5)$ \\
\hline \multicolumn{2}{|l|}{ Gene translocation } \\
\hline Positive & $24(63.2)$ \\
\hline \multicolumn{2}{|l|}{ Lines of previous drug therapy } \\
\hline 1 & $11(28.9)$ \\
\hline 2 & $15(39.5)$ \\
\hline 3 & $6(15.8)$ \\
\hline$\geq 4$ & $6(15.8)$ \\
\hline \multicolumn{2}{|l|}{ Previous antineoplastic agent } \\
\hline Doxorubicin & $28(73.7)$ \\
\hline Ifosphamide & $28(73.7)$ \\
\hline Pazopanib & $10(26.3)$ \\
\hline Eribulin & $7(18.4)$ \\
\hline Gemcitabine & $9(23.7)$ \\
\hline \multicolumn{2}{|l|}{ Other 12 agents } \\
\hline Previous surgery & $33(86.8)$ \\
\hline Previous radiotherapy & $16(42.1)$ \\
\hline
\end{tabular}

\section{Patients and Methods}

We retrospectively reviewed patients with STS who received trabectedin treatment for salvage chemotherapy in our institute from January 2012 to December 2018. This study was approved by the institutional review board of the Cancer Institute Hospital. All patients provided written informed consent prior to starting trabectedin treatment.

Pretreatment disease conditions and treatment response were evaluated by computed tomography (CT). Initial evaluations were made by $\mathrm{CT}$ after two treatment cycles. Trabectedin administration was continued until disease progression, onset of unacceptable adverse events (AEs), or patient refusal. Objective responses were evaluated based on the Response Evaluation Criteria In Solid
Table II. Objective response.

\begin{tabular}{lr}
\hline Best objective response, $\mathrm{n}(\%)$ & $\mathrm{n}=34^{*}$ \\
\hline Complete response (CR) & $0(0)$ \\
Partial response (PR) & $5(14.7)$ \\
Stable disease (SD) & $18(52.9)$ \\
Progressive disease (PD) & $10(29.4)$ \\
Overall response rate (CR+PR) & $5(14.7)$ \\
Disease control rate (ORR+SD) & $24(70.6)$ \\
\hline
\end{tabular}

*Four patients were unable to be assessed.

Tumours (RECIST) version 1.1. Response rates were compared between subgroups using Fisher's exact test. In terms of prognoses, $\mathrm{OS}$ and progression-free survival (PFS) were estimated by the Kaplan-Meier method. AEs were documented based on the Common Terminology Criteria for Adverse Events (CTCAE) version 4.0. All statistical analyses were performed using EZR software (15). A value of $p<0.05$ was considered significant in all analyses.

\section{Results}

A total of 38 patients with unresectable advanced and/or metastatic STS who received trabectedin treatment were included in the study, including 15 who had received trabectedin partly or entirely as part of a clinical trial. The patient characteristics are shown in Table I. The median age was 47 years (range $=21-74$ years) and $44.7 \%$ of patients had L-sarcoma, with the most frequent histological diagnosis being liposarcoma. The primary site in more than half of the cases was the lower limb. Gene translocation was detected in $63.2 \%$ of cases, with the main fusion genes being FUS-CHOP in myxoid liposarcoma, followed by $S Y T-S S X$ in synovial sarcoma. Approximately $70 \%$ of patients had been heavily pretreated with more than two regimens. The main pretreatment regimens were doxorubicin-based regimens, while some patients had received new agents such as pazopanib or eribulin.

The initial dose of trabectedin in most patients was $1.2 \mathrm{mg} / \mathrm{m}^{2}$, as the standard approved dose in Japan, and subsequent administration was continued at the same dose every 3 weeks. If unacceptable AEs occurred, the validity of continuing treatment was considered; if the treatment was continued, the dose was reduced by $0.2 \mathrm{mg} / \mathrm{m}^{2}$ at a time, or the administration interval was prolonged until improvement of the AEs. Dose reduction was possible to a minimum dose of $0.8 \mathrm{mg} / \mathrm{m}^{2}$.

The median follow-up time and median number of trabectedin treatment cycles were 14.5 months (range $=0.5$ 63.2 months) and four cycles (range=1-25 cycles), respectively. Objective CT response evaluations were carried out in 34 of 38 patients, with four patients excluded because 

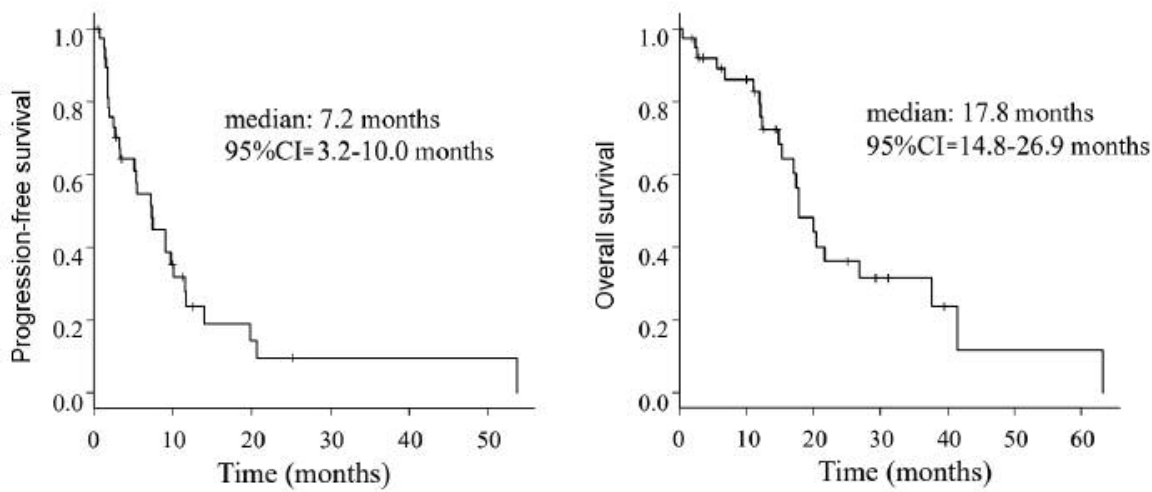

Figure 1. Kaplan-Meier estimates for all patients.

Table III. Adverse events throughout trabectedin treatment.

\begin{tabular}{|c|c|c|c|c|}
\hline & \multicolumn{4}{|c|}{ Patients $(\mathrm{n}=38), \mathrm{n}(\%)$} \\
\hline & Grade 1 & Grade 2 & Grade 3 & Grade 4 \\
\hline Fatigue & $11(28.9)$ & $5(13.2)$ & & \\
\hline Nausea & $12(31.6)$ & $9(23.7)$ & $2(5.3)$ & \\
\hline Vomiting & & $3(5.3)$ & & \\
\hline Neutropenia & $5(13.2)$ & $2(5.3)$ & $12(31.6)$ & $15(39.5)$ \\
\hline Anemia & $19(50.0)$ & $8(21.1)$ & $3(7.9)$ & $2(5.3)$ \\
\hline Thrombocytopenia & $14(36.8)$ & $2(5.3)$ & $7(18.4)$ & $2(5.3)$ \\
\hline Aspartate aminotransferase elevation & $11(28.9)$ & $6(15.8)$ & $15(39.5)$ & $5(13.2)$ \\
\hline Alanine aminotransferase elevation & $4(10.5)$ & $6(15.8)$ & $20(52.6)$ & $7(18.4)$ \\
\hline Febrile neutropenia & & & $4(10.5)$ & \\
\hline
\end{tabular}

of early treatment cessation before the first evaluation. Overall, no patients achieved complete response (CR), five achieved partial response $(\mathrm{PR}=14.7 \%$; 95\% confidence interval $(\mathrm{CI})=5.0-31.0 \%)$, and 18 achieved stable disease $(\mathrm{SD}=52.9 \%$; 95\% CI=35.1-70.2\%) (Table II). The resulting overall response rate (ORR) and disease control rate (DCR) were $14.7 \%(95 \% \mathrm{CI}=52.5-84.9 \%)$ and $67.6 \%(95 \% \mathrm{CI}=49.5-$ $82.6 \%$ ), respectively. Among these 34 patients, some continued treatment for several more cycles after confirmation of PD due to slow disease progression. We determined if L-sarcoma and/or TRS could predict disease control by trabectedin. The DCR tended to be higher in patients with L-sarcoma or TRS, but the difference was not significant (L-sarcoma vs. non-L-sarcoma; 14/17 (82.4\%) vs. 9/17 (52.9\%); $p=0.140$, TRS vs. non-TRS; $15 / 20$ (75\%) vs. $8 / 14(57.1 \%) ; p=0.458)$.

The median PFS and OS in the whole group were 7.3 months $(95 \% \mathrm{CI}=3.2-10.0)$ and 17.8 months $(95 \% \mathrm{CI}=14.8$ 26.9), respectively (Figure 1). The median PFS in patients with L-sarcoma was 9.1 months (95\% CI=3.2-11.6) compared with 5.4 months $(95 \% \mathrm{CI}=1.6-10.0)$ in patients
Table IV. Reasons for dose reduction and cessation of trabectedin.

Patients $(\mathrm{n}=38), \mathrm{n}(\%)$

Reasons for trabectedin dose reduction, $\mathrm{n}(\%)$

No reduction

$26(68.4)$

Gastrointestinal toxicity

Bone marrow suppression

$3(7.9)$

Febrile neutropenia

$10(26.3)$

Increased transaminase

$2(5.3)$

$2(5.3)$

Increased creatine phosphokinase

$1(2.6)$

Reasons for trabectedin cessation, $\mathrm{n}$

Progression disease

23

Adverse event

Withdrawal of consent

with non-L-sarcoma $(p=0.444)$, and the median OS values were 17.8 months $(95 \% \mathrm{CI}=12.0-26.9)$ and 20.4 months (95\%CI=11.9-NA), respectively ( $p=0.669)$ (Figure 2$)$. We also analyzed prognosis in relation to translocation (Figure 3). The median PFS in patients with TRS was 7.4 months 

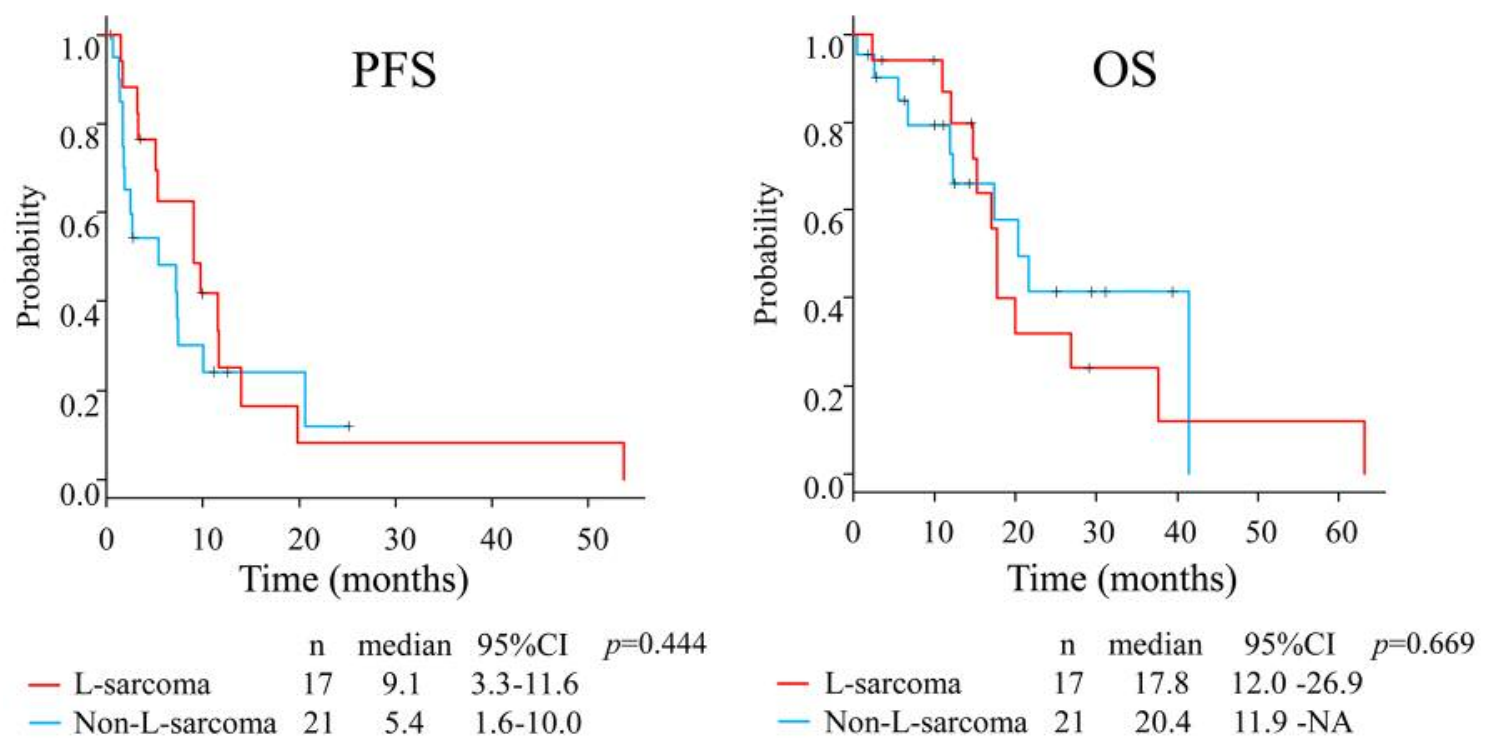

Figure 2. Prognostic comparison between patients with L-sarcoma and non-L-sarcoma.
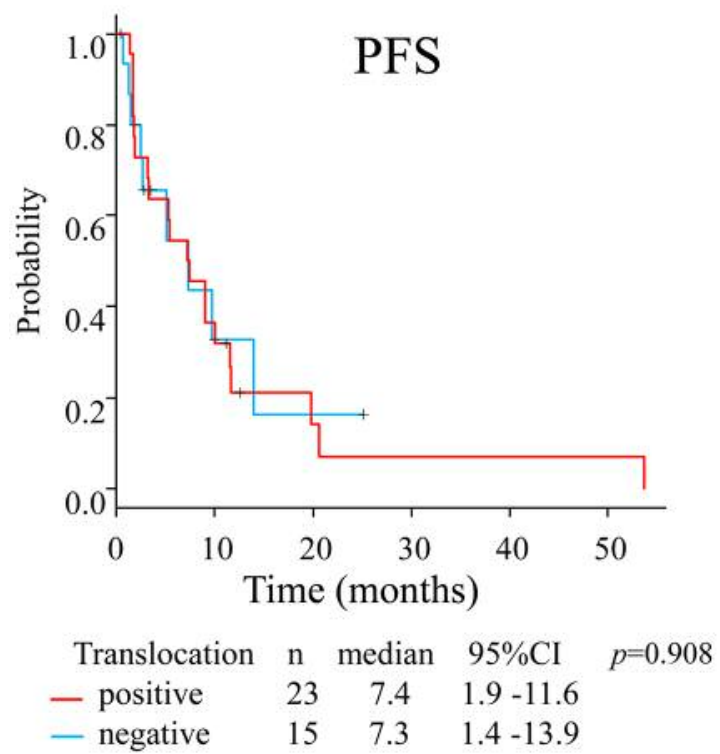

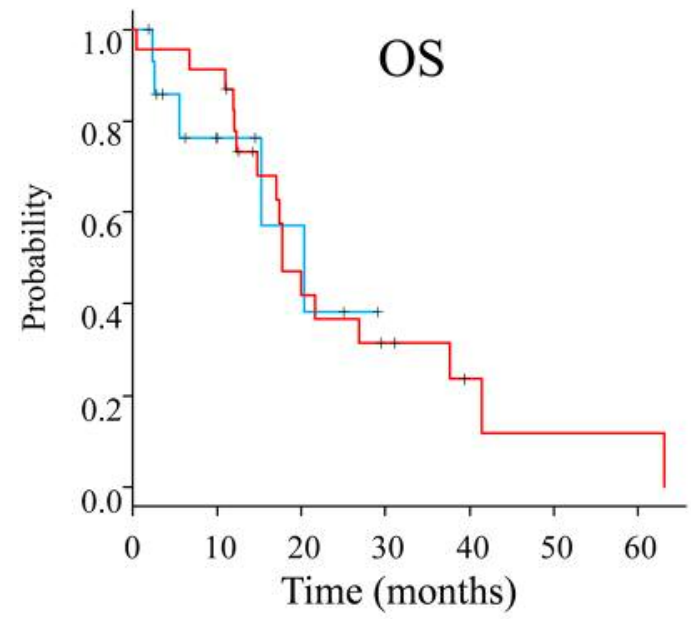

\begin{tabular}{lrcl} 
Translocation & $\mathrm{n}$ & median & \multicolumn{1}{c}{$95 \% \mathrm{CI} \quad p=0.444$} \\
- positive & 23 & 17.8 & $12.4-37.7$ \\
- negative & 15 & 20.4 & 5.5 -NA
\end{tabular}

Figure 3. Prognostic comparison between patients with TRS and non-TRS.

(95\% CI=1.9-11.6) compared with 7.3 months $(95 \% \mathrm{CI}=1.4-$ $13.9)$ in patients with non-TRS $(p=0.908)$, and the equivalent median OS values were 17.8 months $(95 \% \mathrm{CI}=12.4-37.7)$ and 20.4 months $(95 \% \mathrm{CI}=5.5-\mathrm{NA})$, respectively $(p=0.859)$. Thus, although PFS tended to be higher in patients with Lsarcoma, neither L-sarcoma nor TRS was significantly associated with prognosis.
AEs are shown in Tables III and IV. Trabectedin was generally well tolerated, and fatigue, nausea, myelosuppression, and elevated transaminases were the most commonly observed toxicities. The main grade 3-4 AEs were myelosuppression followed by increased transaminases. Some patients with marked myelosuppression received granulocyte colony stimulating factor formulations to allow the dose intensity of 
subsequent trabectedin administrations to be maintained. Elevated transaminases were managed with hepatoprotective drugs such as glycyrrhizin and ursodeoxycholic acid. Febrile neutropenia caused trabectedin cessation or dose reduction in four patients, and there was no cessation and two dose reductions due to elevated transaminase levels. One patient had severe rhabdomyolysis and recovered without renal failure, but did not restart trabectedin treatment.

\section{Discussion}

Trabectedin was approved for the treatment of STS by the European Medicines Agency in 2007 and was approved by the US Food and Drug Administration for L-sarcoma in 2015. Internationally, the efficacy of 24-h infusion of $1.5 \mathrm{mg} / \mathrm{m}^{2}$ trabectedin has been demonstrated, and the approved dose has thus been determined to be $1.5 \mathrm{mg} / \mathrm{m}^{2}(16,17)$. The efficacy of trabectedin for L-sarcoma has been certified in a randomized control trial (14). However, based on the pharmacokinetic results of a phase I study, the recommended dose in Japan was $1.2 \mathrm{mg} / \mathrm{m}^{2}$ with 24 -h infusion, and this is currently the approved dose in Japan, in contrast to the higher dose overseas (18). Furthermore, randomized controlled trials in Japanese patients have only considered TRS (19). The main aim of the current study was thus to confirm the efficacy and safety of the Japan-approved dose of trabectedin in patients with various sarcoma histologies.

The results were comparable to previous reports $(13,14,16$, 19, 20). Notably, although patients with L-sarcoma tended to have better PFS than non-L-sarcoma patients, neither L-sarcoma nor TRS significantly affected the efficacy of trabectedin in terms of prognosis. The median PFS of patients with sarcomas other than TRS was 7.3 months, which was superior to previous reports, and it is possible that prognostic factors other than translocation may be involved $(14,20)$. STS is a rare disease and the number of patients analyzed was therefore limited, making it difficult to demonstrate some factors; however, the results suggest that trabectedin can be considered as a treatment option for STS, even in patients without translocation. Most patients with long-term OS received other treatments after trabectedin, especially with pazopanib. This may account for the overlap in long-term prognosis, even in patients without Lsarcoma or translocation features.

The major clinically important AEs were nausea, neutropenia, and elevated aspartate transaminase/alanine aminotransferase. The incidence of grade 3-4 nausea in overseas clinical trials (trabectedin dose $1.5 \mathrm{mg} / \mathrm{m}^{2}$ ) was about $5 \%$, but the frequencies of grade 3-4 neutropenia and elevated transaminases ranged broadly from 10-60\% $(14,16,20,21)$. The incidence of grade 3 nausea in the current study was $5.3 \%$, which was similar to that in the previous reports. The incidences of grade 3-4 neutropenia and elevated transaminases were both approximately $70 \%$; however, these
AES rarely required treatment cessation, and trabectedin was, thus, considered to be generally well-tolerated.

This study could have been affected by selection bias due to the single-institute retrospective study design. Nevertheless, the results provide evidence for the efficacy and safety of trabectedin at the Japan-approved dose of $1.2 \mathrm{mg} / \mathrm{m}^{2}$, and its non-inferiority compared with standard international dosing. Moreover, trabectedin was effective in STS, regardless of the existence of translocation. Further clinical trials of trabectedin are required, including in combination with other drugs (22, 23 ), to establish its therapeutic potential, and to identify histological factors predicting the efficacy of trabectedin.

\section{Conflicts of Interest}

The Authors have no conflicts of interest to declare regarding this study.

\section{Authors' Contributions}

KK designed the study, and wrote the initial draft of the manuscript. All Authors have contributed to data collection and interpretation, revised the manuscript, and approved the final draft of the manuscript.

\section{Acknowledgements}

The Authors thank all the staff members of the Department of Medical Oncology at the Cancer Institute Hospital of the Japanese Foundation for Cancer Research for diagnosing and treating the patients enrolled in this study.

\section{References}

1 Fletcher CDM, Bridge JA, Hogendoorn PCW and Mertens F (eds.): WHO Classification of tumours of soft tissue and bone 4th edition. Lyon, IARC Press, 2013.

2 Koichi O, Takahiro $\mathrm{H}$ and Akira K: Statistics of soft-tissue sarcoma in Japan: Report from the Bone and Soft Tissue Tumor Registry in Japan. J Orthop Sci 22(4): 755-764, 2017. PMID: 28601416. DOI: 10.1016/j.jos.2017.03.017

3 National Comprehensive Cancer Network. Soft Tissue Sarcoma. (ver. 2.2019). Available at: http://www.nccn.org/professionals/ physician_gls/pdf/sarcoma.pdf

4 Mertens F, Antonescu CR, Hohenberger P, Ladanyi M, Modena P, D'Incalci M, Casali PG, Aglietta $M$ and Alvegård T: Translocation-related sarcomas. Semin Oncol 36(4): 312-323, 2009. PMID: 19664492. DOI: 10.1053/j.seminoncol.2009. 06.004

5 Rowley JD, Le Beau MM and Rabbitts TH (eds.): Chromosomal translocations and genome rearrangements in cancer. Switzerland, Springer International Publishing, pp. 319-354, 2015. DOI: 10.1007/978-3-319-19983-2

6 Edge SB, Byrd DR, Compton CC, Fritz AG, Greene FL and Trotti A (eds.): AJCC cancer staging manual 7th edition. New York, Springer, pp. 291-298, 2010.

7 Santoro A, Tursz T, Mouridsen H, Verweij J, Steward W, Somers R, Buesa J, Casali P, Spooner D and Rankin E: Doxorubicin 
versus CYVADIC versus doxorubicin plus ifosfamide in firstline treatment of advanced soft tissue sarcomas: a randomized study of the European Organization for Research and Treatment of Cancer Soft Tissue and Bone Sarcoma Group. J Clin Oncol 13(7): 1537-1545, 1995. PMID: 7602342. DOI: 10.1200/JCO. 1995.13.7.1537

8 Lorigan P, Verweij J, Papai Z, Rodenhuis S, Le Cesne A, Leahy MG, Radford JA, Van Glabbeke MM, Kirkpatrick A, Hogendoorn PC and Blay JY: Phase III trial of two investigational schedules of ifosfamide compared with standarddose doxorubicin in advanced or metastatic soft tissue sarcoma: a European Organisation for Research and Treatment of Cancer Soft Tissue and Bone Sarcoma Group Study. J Clin Oncol 25: 3144-3150, 2007. PMID: 17634494. DOI: 10.1200/JCO.2006. 09.7717

9 Judson I, Verweij J, Gelderblom H, Hartmann JT, Schöffski P, Blay JY, Kerst JM, Sufliarsky J, Whelan J, Hohenberger P, Krarup-Hansen A, Alcindor T, Marreaud S, Litière S, Hermans C, Fisher C, Hogendoorn PC, dei Tos AP, van der Graaf WT and European Organisation and Treatment of Cancer Soft Tissue and Bone Sarcoma Group: Doxorubicin alone versus intensified doxorubicin plus ifosfamide for first-line treatment of advanced or metastatic soft-tissue sarcoma: a randomised controlled phase 3 trial. Lancet Oncol 15: 415-423, 2014. PMID: 24618336. DOI: 10.1016/S1470-2045(14)70063-4

10 Linch M, Miah AB, Thway K, Judson IR and Benson C: Systemic treatment of soft-tissue sarcoma-gold standard and novel therapies. Nat Rev Clin Oncol 11(4): 187-202, 2014. PMID: 24642677. DOI: 10.1038/nrclinonc.2014.26

11 Gino K, James S and William W: Treatment of advanced, metastatic soft tissue sarcoma: Latest evidence and clinical considerations. Ther Adv Med Oncol 9(8): 533-550, 2017. PMID: 28794805. DOI: $10.1177 / 1758834017712963$

12 Larsen AK, Galmarini CM and D'Incalci M: Unique features of trabectedin mechanism of action. Cancer Chemother Pharmacol 77: 663-671, 2016. PMID: 26666647. DOI: 10.1007/s00280015-2918-1

13 Gajdos C and Elias A: Trabectedin: Safety and efficacy in the treatment of advanced sarcoma. Clin Med Insights Oncol 5: 3543, 2011. PMID: 21499557. DOI: 10.4137/CMO.S4907

14 Le Cesne A, Ray-Coquard I, Duffaud F, Chevreau C, Penel N, Bui Nguyen B, Piperno-Neumann S, Delcambre C, Rios M, Chaigneau L, Le Maignan C, Guillemet C, Bertucci F, Bompas E, Linassier C, Olivier T, Kurtz JE, Even C, Cousin P and Yves Blay J: Trabectedin in patients with advanced soft tissue sarcoma: A retrospective national analysis of the French Sarcoma Group. Eur J Cancer 51: 742-750, 2015. PMID: 25727882. DOI: $10.1016 /$ j.ejca.2015.01.006

15 Kanda Y: Investigation of the freely available easy-to-use software 'EZR' for medical statistics. Bone Marrow Transplant 48: 452-458, 2013. PMID: 23208313. DOI: 10.1038/bmt. 2012.244

16 Le Cesne A, Blay JY, Judson I, Van Oosterom A, Verweij J, Radford J, Lorigan P, Rodenhuis S, Ray-Coquard I, Bonvalot S, Collin F, Jimeno J, Di Paola E, Van Glabbeke M and Nielsen OS: Phase II study of ET-743 in advanced soft tissue sarcomas: A European Organisation for the Research and Treatment of Cancer (EORTC) Soft Tissue and Bone Sarcoma Group Trial. J Clin Oncol 23: 576-584, 2005. PMID: 15659504. DOI: 10.1200/JCO.2005.01.180
17 Demetri GD, von Mehren M, Jones RL, Hensley ML, Schuetze SM, Staddon A, Milhem M, Elias A, Ganjoo K, Tawbi H, Van Tine BA, Spira A, Dean A, Khokhar NZ, Park YC, Knoblauch RE, Parekh TV, Maki RG and Patel SR: Efficacy and safety of trabectedin or dacarbazine for metastatic liposarcoma or leiomyosarcoma after failure of conventional chemotherapy: Results of a Phase III Randomized Multicenter Clinical Trial. J Clin Oncol 34(8): 786-793, 2016. PMID: 26371143. DOI: 10.1200/JCO.2015.62.4734

18 Ueda T, Kakunaga S, Ando M, Yonemori K, Sugiura H, Yamada $\mathrm{K}$ and Kawai A: Phase $\mathrm{I}$ and pharmacokinetic study of trabectedin, a DNA minor groove binder, administered as a 24$\mathrm{h}$ continuous infusion in Japanese patients with soft tissue sarcoma. Invest New Drugs 32: 691-699, 2014. PMID: 2469 6229. DOI: $10.1007 / \mathrm{s} 10637-014-0094-5$

19 Kawai A, Araki N, Sugiura H, Ueda T, Yonemoto T, Takahashi M, Morioka H, Hiraga H, Hiruma T, Kunisada T, Matsumine A, Tanase T, Hasegawa T and Takahashi S: Trabectedin monotherapy after standard chemotherapy versus best supportive care in patients with advanced, translocation-related sarcoma: a randomized, open-label, phase 2 study. Lancet Oncol 16: 406-416, 2015. PMID: 25795406. DOI: 10.1016/S1470-2045(15) 70098-7

20 Samuels BL, Chawla S, Patel S, von Mehren M, Hamm J, Kaiser PE, Schuetze S, Li J, Aymes A and Demetri GD: Clinical outcomes and safety with trabectedin therapy in patients with advanced soft tissue sarcomas following failure of prior chemotherapy: results of a worldwide expanded access program study. Ann Oncol 24: 1703-1709, 2013. PMID: 23385197. DOI: 10.1093/annonc/mds659

21 Calvo E, Azaro A, Rodon J, Dirix L, Huizing M, Senecal FM, LoRusso P, Yee L, Poggesi I, de Jong J, Triantos S, Park YC, Knoblauch RE, Parekh TV, Demetri GD and von Mehren M: Hepatic safety analysis of trabectedin: results of a pharmacokinetic study with trabectedin in patients with hepatic impairment and experience from a phase 3 clinical trial. Invest New Drugs 36(3): 476-486, 2018. PMID: 29177975. DOI: 10.1007/s10637-017-0546-9

22 Martin-Broto J, Pousa AL, de Las Peñas R, García Del Muro X, Gutierrez A, Martinez-Trufero J, Cruz J, Alvarez R, Cubedo R, Redondo A, Maurel J, Carrasco JA, López-Martin JA, Sala Á, Meana JA, Ramos R, Martinez-Serra J, Lopez-Guerrero JA, Sevilla I, Balaña C, Vaz Á, De Juan A, Alemany R and Poveda A: Randomized phase II study of trabectedin and doxorubicin compared with doxorubicin alone as first-line treatment in patients with advanced soft tissue sarcomas: A Spanish Group for Research on Sarcoma Study. J Clin Oncol 34(19): 2294-302, 2016. PMID: 27185843. DOI: 10.1200/JCO.2015.65.3329

23 Grignani G, D’Ambrosio L, Pignochino Y, Palmerini E, Zucchetti M, Boccone P, Aliberti S, Stacchiotti S, Bertulli R, Piana R, Miano S, Tolomeo F, Chiabotto G, Sangiolo D, Pisacane A, Dei Tos AP, Novara L, Bartolini A, Marchesi E, D'Incalci M, Bardelli A, Picci P, Ferrari S and Aglietta M: Trabectedin and olaparib in patients with advanced and nonresectable bone and soft-tissue sarcomas (TOMAS): an openlabel, phase 1b study from the Italian Sarcoma Group. Lancet Oncol 19(10): 1360-1371, 2018. PMID: 30217671. DOI: $10.1016 / \mathrm{S} 1470-2045(18) 30438-8$

Received June 28, 2019

Revised July 9, 2019

Accepted July 10, 2019 